\title{
Welfare Comparisons with a Consumer-Friendly Upstream Firm: Centralized vs. Decentralized Bargaining
}

\author{
Xu Zhang, Xingtang Wang \\ Institute of Industrial Economics, Jinan University, Guangzhou, China \\ Email:explorexu@163.com
}

How to cite this paper: Zhang, $X$. and Wang, X.T. (2017) Welfare Comparisons with a Consumer-Friendly Upstream Firm: Centralized vs. Decentralized Bargaining. Open Journal of Social Sciences, 5, 182-197. https://doi.org/10.4236/jss.2017.53016

Received: February 15, 2017

Accepted: March 20, 2017

Published: March 23, 2017

Copyright (๑) 2017 by authors and Scientific Research Publishing Inc. This work is licensed under the Creative Commons Attribution International License (CC BY 4.0).

http://creativecommons.org/licenses/by/4.0/ (c) (i) Open Access

\begin{abstract}
We investigate the endogenous choice of price (Bertrand) and quantity (Cournot) contract and the resulting social welfare in a vertically related upstream-downstream market with a consumer-friendly upstream firm. We find that choosing price (quantity) contract is the dominant strategy for downstream firms when the two-part-tariff pricing contract is determined through centralized (decentralized) Nash bargaining. Moreover, if the consumer-friendly upstream firm's valuation over consumer surplus is sufficiently high and the product differentiation degree is sufficiently low, centralized bargaining is welfare-superior to decentralized bargaining. On the other hand, if the consumer-friendly upstream firm's valuation over consumer surplus is sufficiently low and the product differentiation degree is sufficiently high, decentralized bargaining is welfare-superior to centralized bargaining. We also show that decentralized bargaining generates higher consumer surplus as compared to centralized bargaining, irrespective of both the product differentiation degree and the upstream firm's valuation over consumer surplus.
\end{abstract}

\section{Keywords}

Consumer-Friendly, Decentralized Bargaining, Centralized Bargaining, Consumer Surplus, Social Welfare

\section{Introduction}

There is a well-established line of research analyzing the effects of Cournot and Bertrand competition on social welfare. Singh and Vives (1984) [1] show that choosing price (quantity) contract is the dominant strategy for both two firms when the goods are complements (substitutes), and a one-tier market is more competitive and efficient when it is characterized by Bertrand competition ra- 
ther than by Cournot competition. In particular, Bertrand competition results in lower prices and products and higher output and consumer and total welfare than Cournot competition. However, the vast majority of products reach the hands of the consumers after going through the various stages of the so-called vertical production chain. Apparently, this implies that a firm which operates in one stage of the vertical chain needs to trade with firms that are active at previous and/or later production stages. A substantial body of the literature has been developed thereafter extending the Singh and Vive s results. For instance, Cheng (1985) [2] and Vives (1985) [3] generalized these results respectively by means of a geographic approach and by considering the $n$-firm oligopoly case with general demand functions. The normal scene is that input suppliers and final goods producers are involving in two-part tariff vertical pricing contracts (Berto Villa-Boas, 2007 [4] and Bonnet and Dubois, 2010 [5]). Alipranti et al. (2014) [6] demonstrate that the standard conclusions about price and quantity competition can be altered in the context of a vertically related market. In particular, they show that when a monopoly input supplier and two final goods producers determine the two-part tariff vertical pricing contracts through a decentralised generalised Nash bargaining process, the equilibrium profits of the final goods producers and social welfare are higher under Cournot competition. Their analysis extends the literature that compares Cournot and Bertrand outcomes in standard one-tier oligopoly markets by considering a vertically related setting. As such their analysis also complements the literature on contracting in vertically related markets (e.g., McAfee and Schwartz, 1995 [7]) by analyzing the role of the mode of downstream competition. On the other hand, Leonard F.S. Wang et al. (2016) [8] aim to revisit the classic question of price and quantity contract where the downstream firms involve in centralized bargaining with an upstream input supplier to determine the two-part tariff vertical pricing contracts. They show that choosing price contract is the dominant strategy for the downstream firms and both Bertrand and Cournot entail equal welfare level.

In our article, we assume a consumer-friendly upstream firm which does not aim to maximize himself profit but to maximize the weighted sum of its own profit and consumer surplus. We find that if the consumer-friendly upstream firm's valuation over consumer surplus is sufficiently high and the product differentiation degree is sufficiently low, centralized bargaining is welfare-superior to decentralized bargaining. On the other hand, if the consumer-friendly upstream firm's valuation over consumer surplus is sufficiently low and the product differentiation degree is sufficiently high, decentralized bargaining is welfare-superior to centralized bargaining.

Our research contributes to several areas of the existing literature. First and foremost, we contribute to the oligopoly theory. In our article, we assume the two downstream firms simultaneously decide whether to adopt quantity contract (Cournot Competition) or price contract (Bertrand Competition). Second, we also contribute to the debate about quantity competition and price competition in a vertical related market. We show that the decision about whether to choose 
quantity or price competition is depend on the bargaining pattern between the downstream firms and the upstream firm. Specifically, if the consumer-friendly upstream firm is involved in a centralized bargaining with the downstream firms, choosing price contract is the best strategy for the final goods producers. Otherwise, quantity contract is the dominant strategy for the downstream firms. Finally, we first introduce an upstream firm which is consumer-friendly to the model, it means the object of the upstream firm is to maximize the weighted sum of its own profit and consumer surplus. We find that if the consumer-friendly upstream firm's valuation over consumer surplus is sufficiently high and the product differentiation degree is sufficiently low, centralized bargaining is welfare-superior to decentralized bargaining.

The remainder of this article is organized as follows. Section 2, we discuss the choices of the two downstream firms. Section 3 provides the analysis of the equilibria. In section 4 , we conclude.

\section{The Model}

Consider a vertical market structure where an upstream monopolist $U$ supplies a homogeneous intermediate input to two downstream firms, denoted by $D_{1}$ and $D_{2}$, respectively, through two-part tariff contracts involving an up-front fixed-fee and a per-unit price. The two downstream firms sell differentiated products in the final good market. We denote the output of downstream firm $i$ by $q_{i},(i=1,2)$. The total output in the final good market is $q=\sum_{i=1}^{2} q_{i}$. We assume that one unit of input is required to produce one unit of the output, and $D_{1}$ and $D_{2}$ can convert the inputs to the final goods without incurring any further cost.

The underlying utility function of the representative consumer is assumed to be $U\left(q_{1}, q_{2}\right)=\left(q_{1}+q_{2}\right)-\frac{q_{2}^{2}}{2}-\frac{q_{1}^{2}}{2}-\gamma q_{1} q_{2}$. Utility maximization yields the following inverse demand function for downstream firm $i: p_{i}=1-q_{i}-\gamma q_{j}$, where $i=1,2$, and $\gamma \in(0.1)$ measures the degree of product differentiation. Clearly, a lower value of $\gamma$ indicates a higher degree of product differentiation. In particular, $\gamma=1$ implies that the goods of the two downstream firms are perfect substitutes, and $\gamma=0$ implies that their products are completely different. Clearly, the resulting consumer surplus is $C S=\frac{q_{2}^{2}}{2}+\frac{q_{1}^{2}}{2}+\gamma q_{1} q_{2}$.

The upstream firm $U$ is assumed to be a consumer-friendly one, whose objective is to maximize the weighted sum of its own profit and consumer surplus, i.e., $V_{U}=\pi_{U}+\alpha C S$, where $\alpha(0 \leq \alpha \leq 1)$ denotes the degree of the upstream firm's concern over consumer surplus.

We then consider a three-stage game. At the first stage, the two downstream firms simultaneously decide whether to adopt quantity contract or price contract. At the second stage, the upstream firm $U$ involves in a centralized (or decentralized) bargaining with downstream firms to determine the terms of the two-part tariff contracts involving an up-front fixed-fee, $F_{i}$, and a per-unit 
price, $\omega_{i}$, where $i=1,2$. At the third stage, all the enterprises decide on their competition pattern given the result of stage 1 . We solve the game through backward induction. We start our discussion at stage 3. Totally, there are four competition modes:

\subsection{Both Downstream Firms Adopt Quantity Contracts ( $q q)$}

In this case, each $D_{i}$ selects $q_{i}$ to maximize its own profit:

$$
\operatorname{Max} \pi_{i}^{q q}=\left(1-\omega_{i}-\gamma q_{j}\right) q_{i}-\omega_{i} q_{i}-F_{i}, \quad i, j=1,2, \quad i \neq j .
$$

The resulting reaction functions are:

$$
q_{i}=\frac{1-\omega_{i}-\gamma q_{j}}{2} i, j=1,2, \quad i \neq j .
$$

From (1) and (2), we obtain the equilibrium quantity and prices:

$$
q_{i}=\frac{(2-\gamma)-2 \omega_{i}+\gamma \omega_{j}}{4-\gamma^{2}}, p_{i}=\frac{2-\gamma+\left(2-\gamma^{2}\right) \omega_{i}+\gamma \omega_{j}}{4-\gamma^{2}}, i, j=1,2, i \neq j .
$$

It is obvious that the final production of each downstream firm is negatively correlated with its own input price and positively correlated with its rival's input price. Moreover, each downstream firm's final product price increase with the downstream firms' input prices.

From (3), the profit equation in (1) can be further reduced to

$$
\pi_{i}^{q q}=\left(q_{i}^{2}\right)-F_{i}, \quad i, j=1,2, \quad i \neq j .
$$

\subsection{Both Downstream Firms Adopt Price Contracts ( $p p)$}

In this case, the direct demand function is

$q_{i}=\frac{(1-\gamma)-p_{i}+\gamma q_{j}}{1-\gamma^{2}}, i, j=1,2, \quad i \neq j$. Each $D_{i}$ chooses $p_{i}$ to maximize its own profit:

$$
\operatorname{Max} \pi_{i}^{p p}=\left(p_{i}-\omega_{i}\right) \frac{\left(1-p_{i}\right)-\gamma\left(1-p_{j}\right)}{1-\gamma^{2}}-F_{i}, i, j=1,2, i \neq j .
$$

The first-order conditions give rise to the following reaction functions:

$$
p_{i}=\frac{(1-\gamma)+\gamma p_{j}+\omega_{i}}{2}, i, j=1,2, \quad i \neq j
$$

From (5) and (6), we get the equilibrium prices and outputs of each downstream firm's final product:

$$
\begin{aligned}
& q_{i}=\frac{(1-\gamma)(2+\gamma)-\left(2-\gamma^{2}\right) \omega_{i}+\gamma \omega_{j}}{\left(4-\gamma^{2}\right)\left(1-\gamma^{2}\right)}, \\
& p_{i}=\frac{(1-\gamma)(2+\gamma)+2 \omega_{i}+\gamma \omega_{j}}{4-\gamma^{2}}, \quad i, j=1,2, i \neq j .
\end{aligned}
$$

From (7), the profit function of downstream firm $i$ in (5) can be further reduced to:

$$
\pi_{i}^{p p}=\left(1-\gamma^{2}\right)\left(q_{i}^{2}\right)-F_{i}, \quad i, j=1,2, \quad i \neq j
$$




\section{3. $D_{1}$ Chooses Price Contract and $D_{2}$ Chooses Quantity Contract $(p q)$}

In this case, $D_{1}$ chooses $p_{1}$ and $D_{2}$ chooses $q_{2}$ to maximize their profits simultaneously:

$$
\begin{gathered}
\operatorname{Max} \pi_{1}=\left(p_{1}-\omega_{1}\right) \frac{\left(1-p_{1}\right)-\gamma\left(1-p_{2}\right)}{1-\gamma^{2}}-F_{1} . \\
\operatorname{Max} \pi_{2}=\left(1-\omega_{2}-\gamma q_{1}\right) q_{2}-\omega_{2} q_{2}-F_{2} .
\end{gathered}
$$

The first order conditions of (9) and (10) yield the equilibrium price charged by $D_{1}$ and the equilibrium output level chosen by $D_{2}$ :

$$
p_{1}=\frac{(1-\gamma)(2+\gamma)+2\left(1-\gamma^{2}\right) \omega_{1}+\gamma \omega_{2}}{4-3 \gamma^{2}}, q_{2}=\frac{(2-\gamma)+\gamma \omega_{1}-2 \omega_{2}}{4-3 \gamma^{2}} .
$$

Thus, the profit functions in (9) and (10) can be further reduced to:

$$
\begin{gathered}
\pi_{1}^{p q}=\left(q_{1}^{2}\right)-F_{1}, \\
\pi_{2}^{p q}=\left(1-\gamma^{2}\right)\left(q_{2}^{2}\right)-F_{2} .
\end{gathered}
$$

\section{4. $D_{1}$ Chooses Quantity Contract and $D_{2}$ Chooses Price Contract $(q p)$}

In this case, $D_{1}$ chooses $q_{1}$ and $D_{2}$ chooses $p_{2}$ to maximize their own profits:

$$
\begin{gathered}
\operatorname{Max} \pi_{1}^{q p}=\left(1-\omega_{1}-\gamma q_{2}\right) q_{1}-\omega_{1} q_{1}-F_{1}, \\
\operatorname{Max} \pi_{2}^{q p}=\left(p_{2}-\omega_{2}\right) \frac{\left(1-p_{2}\right)-\gamma\left(1-p_{1}\right)}{1-\gamma^{2}}-F_{2} .
\end{gathered}
$$

The first order conditions of (14) and (15) determines the equilibrium quantity of $D_{1}$ and the equilibrium price of $D_{2}$ :

$$
q_{1}=\frac{(2-\gamma)+\gamma \omega_{2}-2 \omega_{1}}{4-3 \gamma^{2}}, p_{2}=\frac{(1-\gamma)(2+\gamma)+2\left(1-\gamma^{2}\right) \omega_{2}+\gamma \omega_{1}}{4-3 \gamma^{2}} .
$$

Thus, the profit functions in (14) and (15) can be further reduced to:

$$
\begin{gathered}
\pi_{1}^{p q}=\left(1-\gamma^{2}\right)\left(q_{1}^{2}\right)-F_{1}, \\
\pi_{1}^{p q}=\left(q_{2}^{2}\right)-F_{2} .
\end{gathered}
$$

\section{Equilibrium Analysis}

\subsection{Centralized Bargaining}

In this part, we assume that the consumer-friendly upstream firm involves in a centralized bargaining with the downstream firms. At stage two of game, the upstream firm and downstream firms determine the terms of the two-part tariff contract by maximizing the following generalized Nash bargaining expression:

$$
\operatorname{Max}\left[\alpha C S+\sum_{i=1}^{2}\left(q_{i}^{\rho} \omega_{i}^{\rho}+F_{i}^{\rho}\right)\right]^{\beta} *\left[\sum_{i=1}^{2} \pi_{i}^{\rho}\right]^{(1-\beta)},
$$


where $\alpha$ denotes the consumer-friendly upstream firm's valuation over consumer surplus, $\rho$ denotes the mode of downstream competition. And $q_{i}^{\rho}$ and $\pi_{i}^{\rho}$ denote the output and net profit of the final goods producers, $\beta$ (resp. $(1-\beta)$ ) shows the bargaining power of the upstream firm (resp. downstream firms). We restrict the range of $\beta: \beta \in(0,1)$. If $\beta=1, \omega_{i}$ and $F_{i}$ are set by the upstream firm and if $\beta=0, \omega_{i}$ and $F_{i}$ are set by the downstream firms.

Maximizing the above with respect to $F_{i}$ gives the following:

$$
\begin{aligned}
F_{i}^{\rho}= & \frac{1}{2} \beta \sum_{i=1}^{2}\left[\left(1-q_{i}^{\rho}-\gamma q_{j}^{\rho}-\omega_{i}^{\rho}\right) q_{i}^{\rho}\right] \\
& -(1-\beta) \sum_{i=1}^{2} q_{i}^{\rho}\left[2(1+\alpha) \omega_{i}^{\rho}-\alpha\left(1-p_{j}^{\rho}\right)\right] .
\end{aligned}
$$

Maximizing (16) subject to (1)-(15) and (17) gives the equilibrium input prices of downstream firms under the different modes of downstream competition as:

$$
\omega_{1}^{q q}=\omega_{2}^{q q}=\frac{\alpha-\gamma+\alpha \gamma}{(-2+\alpha)(1+\gamma)}
$$

(where both downstream firms choose quantity contracts),

$$
\omega_{1}^{p p}=\omega_{2}^{p p}=\frac{\alpha-\gamma}{-2+\alpha}
$$

(where both downstream firms choose price contracts),

$$
\omega_{1}^{p q}=\frac{\alpha+(-1+\alpha) \gamma}{(-2+\alpha)(1+\gamma)}, \quad \omega_{2}^{p q}=\frac{\alpha-\gamma}{-2+\alpha}
$$

(where $D_{1}$ adopts price contract and $D_{2}$ adopts quantity contract),

$$
\omega_{1}^{q p}=\frac{\alpha-\gamma}{-2+\alpha}, \quad \omega_{2}^{q p}=\frac{\alpha+(-1+\alpha) \gamma}{(-2+\alpha)(1+\gamma)}
$$

(where $D_{1}$ adopts quantity contract and $D_{2}$ adopts price contract).

At the stage one, each downstream firm simultaneously makes a choice whether to adopt quantity contract or price contract. We can get the equilibrium outcomes shown in Table 1.

We can find that consumer surplus and social welfare will not change irrespective of the mode of downstream competition. As

$\pi_{1 c}^{p q}-\pi_{1 c}^{q q}=\pi_{1 c}^{p p}-\pi_{1 c}^{p q}=\pi_{2 c}^{p q}-\pi_{2 c}^{q q}=\pi_{2 c}^{p p}-\pi_{2 c}^{p q}=\frac{\gamma^{2}}{2(1+\gamma)^{2}(-2+\alpha)^{2}}>0$, for the downstream firms, choosing price contract is the best strategy for the final goods producers, which is similar to Leonard F.S. Wang et al. (2016). When the downstream firms choose price contract, the profits of the upstream firm is:

$\Pi_{c}^{p p}=\frac{2 \beta-\alpha(1+\beta)}{(-2+\alpha)^{2}(1+\gamma)}$. And in this case, the social welfare is

$S W_{c}^{p p}=\frac{3-2 \alpha}{(2-\alpha)^{2}(1+\gamma)}$, the consumer surplus is $C S_{c}^{p p}=\frac{1}{(2-\alpha)^{2}(1+\gamma)}$ and 
Table 1. Equilibrium outcomes under centralized bargaining.

\begin{tabular}{|c|c|c|c|}
\hline Competition model & Profit of the downstream firms & Social welfare & Consumer surplus \\
\hline$q q$ & $\pi_{i c}^{q q}=\pi_{j c}^{q q}=\frac{1-\beta}{2(2-\alpha)(1+\gamma)}$ & $\frac{3-2 \alpha}{(2-\alpha)^{2}(1+\gamma)}$ & $\frac{1}{(2-\alpha)^{2}(1+\gamma)}$ \\
\hline$p p$ & $\pi_{i c}^{p p}=\pi_{j c}^{p p}=\frac{1-\beta}{2(2-\alpha)(1+\gamma)}$ & $\frac{3-2 \alpha}{(2-\alpha)^{2}(1+\gamma)}$ & $\frac{1}{(2-\alpha)^{2}(1+\gamma)}$ \\
\hline$p q$ & $\begin{array}{l}\pi_{i c}^{p q}=\frac{2+\alpha(-1+\beta)(1+\gamma)-2 \beta(1+\gamma)+\gamma(2+\gamma)}{2(-2+\alpha)^{2}(1+\gamma)^{2}} \\
\pi_{j c}^{p q}=\frac{2-(-2+\gamma) \gamma+\alpha(-1+\beta)(1+\gamma)-2 \beta(1+\gamma)}{2(-2+\alpha)^{2}(1+\gamma)^{2}}\end{array}$ & $\frac{3-2 \alpha}{(2-\alpha)^{2}(1+\gamma)}$ & $\frac{1}{(2-\alpha)^{2}(1+\gamma)}$ \\
\hline$q p$ & $\begin{array}{l}\pi_{i c}^{p q}=\frac{2+\alpha(-1+\beta)(1+\gamma)-2 \beta(1+\gamma)+\gamma(2+\gamma)}{2(-2+\alpha)^{2}(1+\gamma)^{2}} \\
\pi_{j c}^{p q}=\frac{2-(-2+\gamma) \gamma+\alpha(-1+\beta)(1+\gamma)-2 \beta(1+\gamma)}{2(-2+\alpha)^{2}(1+\gamma)^{2}}\end{array}$ & $\frac{3-2 \alpha}{(2-\alpha)^{2}(1+\gamma)}$ & $\frac{1}{(2-\alpha)^{2}(1+\gamma)}$ \\
\hline
\end{tabular}

the profit of downstream firm $i$ is $\pi_{i c}^{p p}=\frac{1-\beta}{2(2-\alpha)(1+\gamma)}$.

Social welfare comprised with three major part-consumer surplus, upstream firm's profits and downstream firms' profits. So the effect of a change in $\alpha$ on social welfare can be decomposed into three different effects as follow: $\frac{\mathrm{d} S W_{c}^{p p}}{\mathrm{~d} \alpha}=\frac{\mathrm{d} C S_{c}^{p p}}{\mathrm{~d} \alpha^{+}}+\frac{\mathrm{d} \Pi_{c}^{p p}}{\mathrm{~d} \alpha^{-}}+\frac{\mathrm{d} \pi_{i c}^{p p}}{\mathrm{~d} \alpha^{+}} 1$. The first term on the right-hand side captures the direct effect of a change in $\alpha$ on consumer surplus. We know that the final product price decline and output rises, can make the consumer surplus rise. So consumer-friendly upstream firm reduces the intermediate product prices to lower the price of the final product, increase the output of the final product, to increase the consumer surplus. The degree of the upstream firm's concern over consumer surplus $(\alpha)$ rises leading to the downstream manufacturers' output increased $\left(\frac{\mathrm{d} q_{i}^{p p}}{\mathrm{~d} \alpha}=\frac{1}{(2-\alpha)^{2}(1+\gamma)}\right)$, price fell $\left(\frac{\mathrm{d} p_{i c}^{p p}}{\mathrm{~d} \alpha}=-\frac{1}{(2-\alpha)^{2}}<0\right)$. So the rise of $\alpha$ is beneficial to the consumer surplus. The second and third terms on the right-hand side denotes the direct effect of a change in $\alpha$ on the profits of upstream and downstream firms. Consumer-friendly upstream firm reduce the intermediate product prices to rise the consumer surplus, which is damage to its profits $\left(\frac{\mathrm{d} \Pi_{c}^{p p}}{\mathrm{~d} \alpha}<0\right)$ and beneficial to the profits of downstream firms $\left(\frac{\mathrm{d} \pi_{i c}^{p p}}{\mathrm{~d} \alpha}>0\right)$. As $\frac{\mathrm{d} S W_{c}^{p p}}{\mathrm{~d} \alpha}=\frac{2(-1+\alpha)}{(1+\gamma)(-2+\alpha)^{3}}>0$, the sum effect of a change in $\alpha$ on consumer surplus and downstream is stronger than downstream firm.

Lemma 1. Social welfare is positive correlated with the degree of the upstream firm's concern over consumer surplus under centralized bargaining.

${ }^{1}$ Where $\pi_{i c}^{p p}$ denotes the net profit of the downstream firms and $\Pi_{c}^{p p}$ denotes the net profit of the upstream firm over the centralized bargaining. “+” denotes Positive and “-” denotes negative. 


\subsection{Decentralized Bargaining}

In this part, we will investigate the situation that the decentralized bargaining between the consumer-friendly upstream firm and the downstream firms. At stage two of the game, the upstream firm and downstream firms adopt the terms of the two-part tariff contract by maximizing the following generalized Nash bargaining expression:

$$
\begin{aligned}
& \operatorname{Max}\left[\alpha\left(C S_{1}^{\rho}-C S_{2}^{\rho}\right)+\sum_{i=1}^{2}\left(q_{i}^{\rho} \omega_{i}^{\rho}+F_{i}^{\rho}\right)-\omega_{j}^{\rho} \frac{\left(1-\omega_{j}^{\rho}\right)}{2}+F_{j}^{\rho}\right]^{\beta} *\left[\pi_{i}^{\rho}\right]^{1-\beta}, \\
& i, j=1,2, i \neq j
\end{aligned}
$$

where $C S_{1}^{\rho}=\frac{\left(q_{1}^{\rho}\right)^{2}+\left(q_{2}^{\rho}\right)^{2}+2 \gamma q_{1}^{\rho} q_{2}^{\rho}}{2}$ denotes the consumer surplus that two downstream firms in the downstream market. $C S_{2}^{\rho}=\frac{\frac{\left(1-\omega_{j}^{\rho}\right)^{2}}{2}}{2}$ represents the consumer surplus and $\omega_{j}^{\rho} \frac{\left(1-\omega_{j}^{\rho}\right)}{2}+F_{j}^{\rho}$ is $U_{\text {s }}$ profits when the upstream firm's negotiation with $D_{i}$ breakdown and $D_{j}$ acts as a monopolist in the downstream market, i.e., it produces the monopoly quantity.

Maximizing the above with respect to $F_{i}$ gives the following

$$
F_{i}^{\rho}=(-1+\beta)\left[\alpha\left(C S_{1}^{\rho}-C S_{2}^{\rho}\right)+\sum_{i=1}^{2}\left(q_{i}^{\rho} \omega_{i}^{\rho}\right)-\frac{\left(1+\omega_{j}^{\rho}\right)}{2} \frac{\left(1-\omega_{j}^{\rho}\right)}{2}\right]+\beta\left(1-q_{i}^{\rho}-\gamma q_{j}^{\rho}-\omega_{i}^{\rho}\right) q_{i}^{\rho}
$$

In this case, we can get the equilibrium wholesale prices of downstream firms under the different modes of competition.

$$
\omega_{1}^{q q}=\omega_{2}^{q q}=\frac{-\gamma^{2}+\alpha(-2+\gamma)(1+\gamma)}{4-2 \gamma^{2}+\alpha(-2+\gamma)(1+\gamma)}
$$

(where both downstream firms choose quantity contracts),

$$
\omega_{1}^{p p}=\omega_{2}^{p p}=\frac{\gamma^{2}-\alpha(2+\gamma)}{4-\alpha(2+\gamma)}
$$

(where both downstream firms choose price contracts),

$$
\begin{aligned}
& \omega_{1}^{p q}=\frac{4 \gamma^{2}+\alpha^{2}(1+\gamma)\left(-4+3 \gamma^{2}\right)+\alpha(8+\gamma(12-\gamma(2+5 \gamma)))}{(1+\gamma)\left(-4(-2+\alpha)^{2}+(8+\alpha(-8+3 \alpha)) \gamma^{2}\right)}, \\
& \omega_{2}^{p q}=\frac{2 \gamma^{2}\left(-2+\gamma^{2}\right)+\alpha^{2}(1+\gamma)\left(-4+3 \gamma^{2}\right)-\alpha(1+\gamma)(-8+\gamma(-4+\gamma(2+3 \gamma)))}{(1+\gamma)\left(-4(-2+\alpha)^{2}+(8+\alpha(-8+3 \alpha)) \gamma^{2}\right)},
\end{aligned}
$$

(where $D_{1}$ adopts price contract and $D_{2}$ adopts quantity contract),

$$
\begin{aligned}
& \omega_{1}^{q p}=\frac{2 \gamma^{2}\left(-2+\gamma^{2}\right)+\alpha^{2}(1+\gamma)\left(-4+3 \gamma^{2}\right)-\alpha(1+\gamma)(-8+\gamma(-4+\gamma(2+3 \gamma)))}{(1+\gamma)\left(-4(-2+\alpha)^{2}+(8+\alpha(-8+3 \alpha)) \gamma^{2}\right)}, \\
& \omega_{2}^{q p}=\frac{4 \gamma^{2}+\alpha^{2}(1+\gamma)\left(-4+3 \gamma^{2}\right)+\alpha(8+\gamma(12-\gamma(2+5 \gamma)))}{(1+\gamma)\left(-4(-2+\alpha)^{2}+(8+\alpha(-8+3 \alpha)) \gamma^{2}\right)},
\end{aligned}
$$


(where $D_{1}$ adopts quantity contract and $D_{2}$ adopts price contract).

At the stage 1, each downstream firm simultaneously makes a choice whether to adopt quantity contract or price contract. We can get the equilibrium outcomes as follows (Table 2):

As $\operatorname{Min}\left(\pi_{1 d}^{q q}-\pi_{1 d}^{p q}\right) \geq 0, \operatorname{Min}\left(\pi_{1 d}^{q p}-\pi_{1 d}^{p p}\right) \geq 0, \quad \operatorname{Min}\left(\pi_{2 d}^{p q}-\pi_{2 d}^{p p}\right) \geq 0$, $\operatorname{Min}\left(\pi_{2 d}^{q q}-\pi_{2 d}^{q p}\right) \geq 0$, for the downstream firms, choosing quantity contract is the dominant strategy which is similar to Maria Alipranti (2014). When the downstream firms choices quantity contract, the profits of upstream firm is

$$
\Pi_{d}^{q q}=\frac{(-2+\gamma)\left\{4 \gamma^{3}-4 \beta(-2+\gamma)\left(-2+\gamma^{2}\right)+\alpha(-2+\gamma)\left[-4(1+\beta)-8 \gamma+3(-1+\beta) \gamma^{2}\right]\right\}}{4\left(4-2 \gamma^{2}+\alpha(-2+\gamma)(1+\gamma)\right)^{2}} .
$$

And in this case, the social welfare is

$$
\begin{aligned}
& S W_{d}^{q q}=\frac{(2-\gamma)[6+2 \alpha(-2+\gamma)(1+\gamma)-\gamma(1+3 \gamma)]}{\left(4-2 \gamma^{2}+\alpha(-2+\gamma)(1+\gamma)\right)^{2}}, \text { the consumer surplus is } \\
& C S_{d}^{q q}=\frac{(2-\gamma)^{2}(1+\gamma)}{\left(4-2 \gamma^{2}+\alpha(-2+\gamma)(1+\gamma)\right)^{2}} \text { and the profit of downstream firm is } \\
& \pi_{i d}^{q q}=\frac{(1-\beta)(-2+\gamma)^{2}\left[8-4 \gamma^{2}+\alpha\left(-4+3 \gamma^{2}\right)\right]}{8\left(4-2 \gamma^{2}+\alpha(-2+\gamma)(1+\gamma)\right)^{2}} .
\end{aligned}
$$

What is the relationship between social welfare and the degree of the upstream firm's concern over consumer surplus $(\alpha)$ ? Same as over the centralized bargaining, the effect of a change in $\alpha$ can be decomposed into three different effects as follow: $\frac{\mathrm{d} S W_{d}^{p p}}{\mathrm{~d} \alpha}=\frac{\mathrm{d} C S_{d}^{p p}}{\mathrm{~d} \alpha^{+}}+\frac{\mathrm{d} \Pi_{d}^{p p}}{\mathrm{~d} \alpha^{-}}+\frac{\mathrm{d} \pi_{i d}^{p p}}{\mathrm{~d} \alpha^{+}}$. The degree of upstream firm's concern about consumer surplus is positive correlated with consumer surplus and the net profit of the downstream firms, negatively correlated with the net profit of the upstream. But Social welfare and the attention of consumer surplus is inverted $U$-shaped relationship in this case. In other word, when the degree of concern is relatively low $\left(0<\alpha<\frac{2-\gamma-\gamma^{2}}{2+\gamma-\gamma^{2}}\right)$, the sum effect of a change in $\alpha$ on consumer surplus and downstream is stronger than upstream firm and in this case the social welfare increase as $\alpha$ rises. And when the degree of concern is relatively high $\left(\frac{2-\gamma-\gamma^{2}}{2+\gamma-\gamma^{2}}<\alpha<1\right)$, the sum effect of a change in $\alpha$ on consumer surplus and downstream is weaker than upstream firm, and in this case the social welfare falls as $\alpha$ rises. As shown in Figure 1, the degree of the upstream firm's concern over consumer surplus is positive correlated with the social welfare below the line (area $A$ ) and negatively correlated with the social welfare above the line (area $B$ ). And when the coordinate are on the line, the total surplus in the amount of the increase is equal to the amount of the reduction.

Lemma 2. Social welfare and the degree of upstream firm's concern about consumer surplus is inverted $U$-shaped relationship under decentralized bargaining.

Proof: 


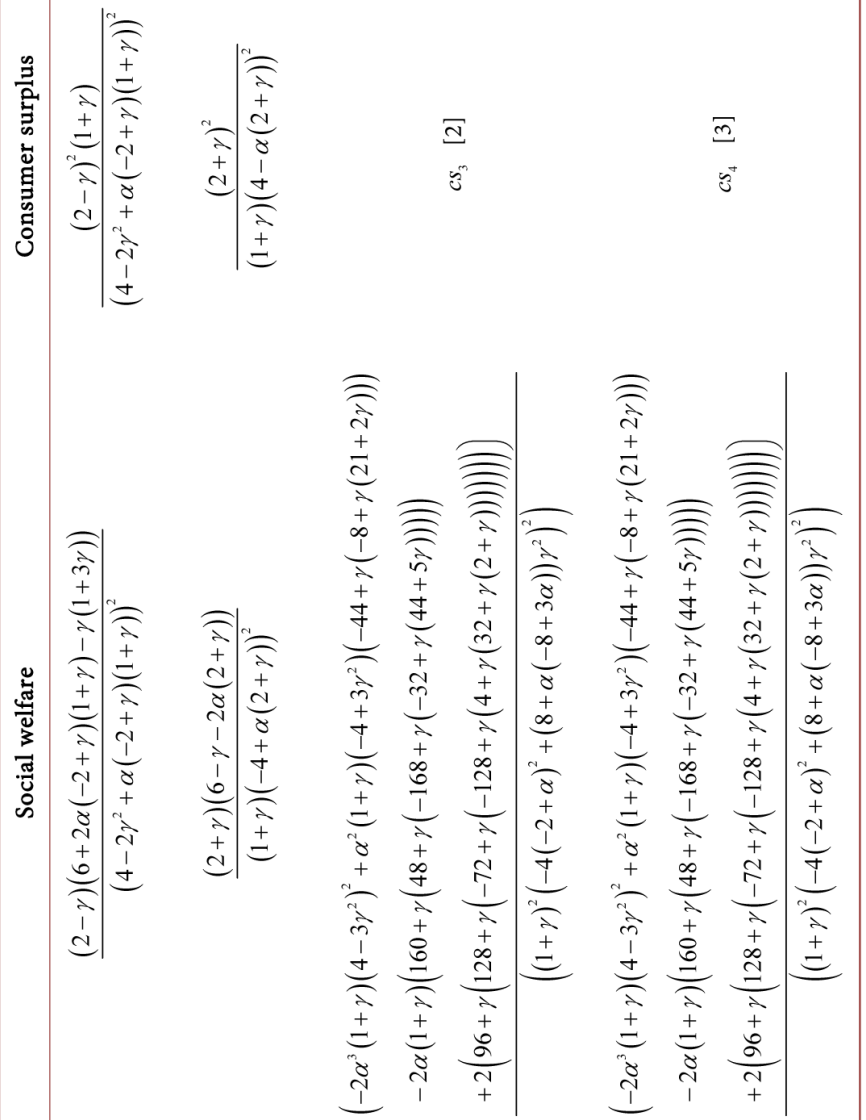

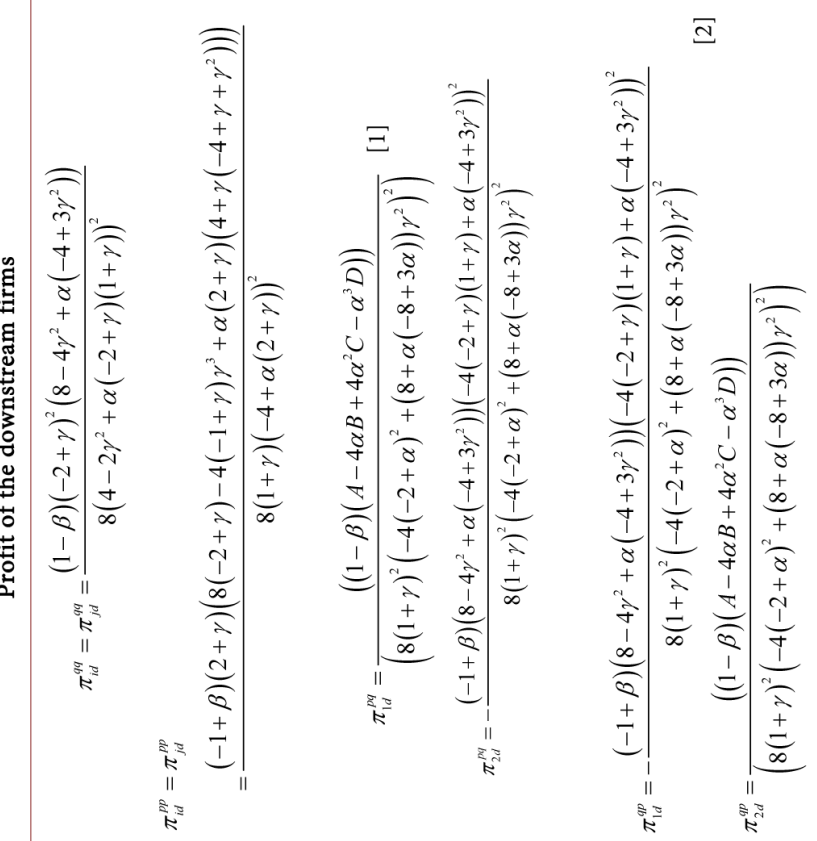

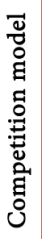

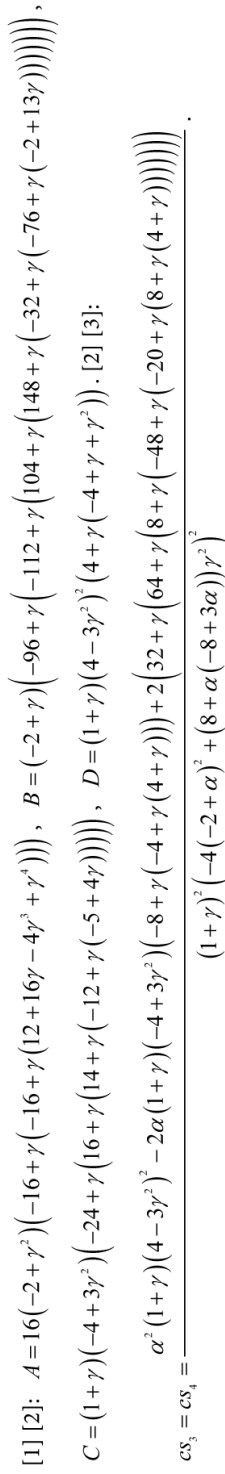




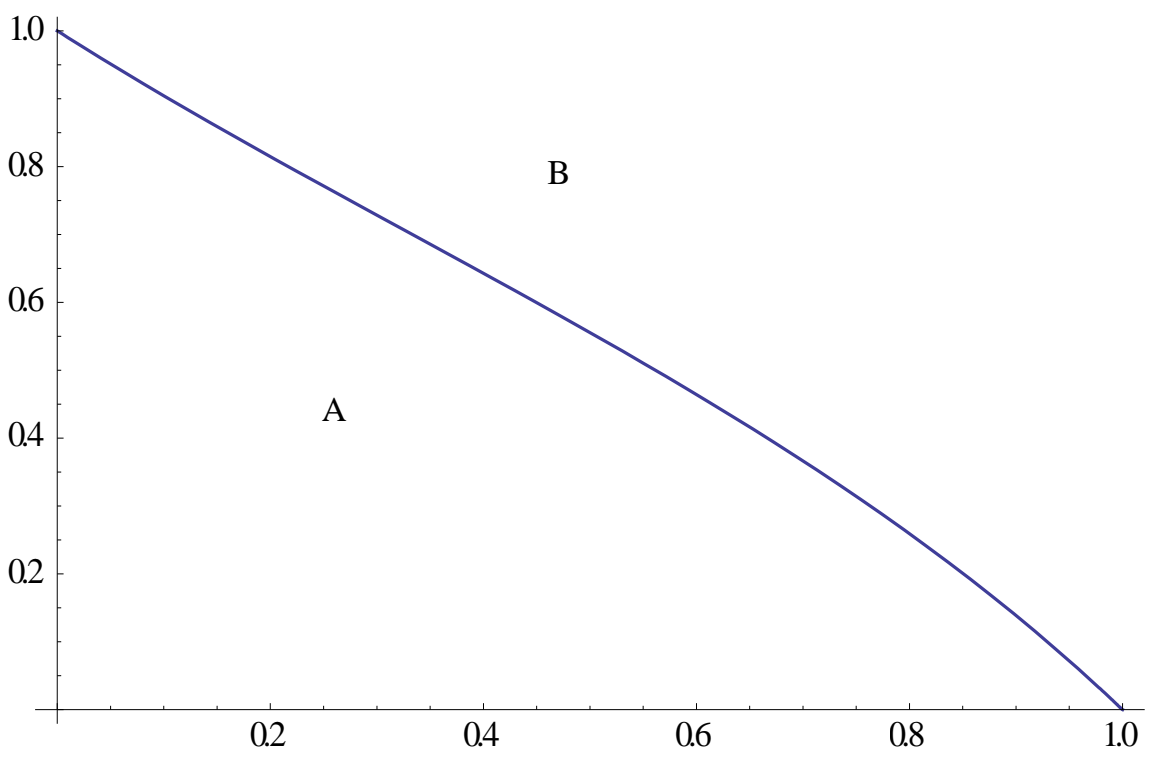

Figure 1. The relationship between social welfare and $\alpha$ ( $X$-axis is $\gamma, Y$-axis is $\alpha)$.

$$
\begin{aligned}
\frac{\mathrm{d} S W_{d}^{p p}}{\mathrm{~d} \alpha} & =\frac{\mathrm{d} C S_{d}^{p p}}{\mathrm{~d} \alpha^{+}}+\frac{\mathrm{d} \Pi_{d}^{p p}}{\mathrm{~d} \alpha^{-}}+\frac{\mathrm{d} \pi_{i d}^{p p}}{\mathrm{~d} \alpha^{+}} \\
& =\frac{2(-2+\gamma)^{2}(1+\gamma)(\alpha(-2+\gamma)(1+\gamma)-(-1+\gamma)(2+\gamma))}{\left(4-2 \gamma^{2}+\alpha(-2+\gamma)(1+\gamma)\right)^{3}},
\end{aligned}
$$

when

$$
0<\alpha<\frac{2-\gamma-\gamma^{2}}{2+\gamma-\gamma^{2}}, \frac{\mathrm{d} S W_{d}^{p p}}{\mathrm{~d} \alpha}>0
$$

when

$$
\frac{2-\gamma-\gamma^{2}}{2+\gamma-\gamma^{2}}<\alpha<1, \frac{\mathrm{d} S W_{d}^{p p}}{\mathrm{~d} \alpha}<0
$$

and when

$$
\frac{2-\gamma-\gamma^{2}}{2+\gamma-\gamma^{2}}=\alpha, \frac{\mathrm{d} S W_{d}^{p p}}{\mathrm{~d} \alpha}=0
$$

According to the content of the above, we can get the following corollary:

Corollary 1. When the upstream firm is a consumer-friendly firm, the social welfare and the consumer surplus is greater than a profit maximization enterprise.

If the upstream firm is profit-maximizing, the endogenous choice of competition mode in the downstream market will not change. And the social welfare is $S W_{p c}=\frac{3}{4(1+\gamma)}{ }^{2}$, the consumer surplus is $C S_{p c}=\frac{1}{4(1+\gamma)}$ under the centralized bargaining, the social welfare is $S W_{p d}=\frac{(2-\gamma)\left(6-\gamma-3 \gamma^{2}\right)}{4\left(2-\gamma^{2}\right)^{2}}$, the consumer

${ }^{2}$ In this case the subscript $p c(p d)$ denote the upstream firm is profit-maximizing and the bargaining model is centralized (decentralized) bargaining. 
surplus is $C S_{p d}=\frac{(2-\gamma)^{2}(1+\gamma)}{4\left(2-\gamma^{2}\right)^{2}}$ under the decentralized bargaining. We can

find that: $S W_{c}-S W_{p} \geq 0$ and $C S_{c}-C S_{p} \geq 0$.

$$
S W \uparrow=C S \uparrow+N \Pi \downarrow^{3} .
$$

Equation (23) means that consumer surplus rise and total profits of downstream and upstream firms declined, but the social welfare will rise when the upstream firm is consumer-friendly. If the upstream firm is a consumer-friendly firm, the upstream firm not only pay attention to its own profit, but also concerned about the consumer surplus in the bargaining process. As $\frac{\mathrm{d} p}{\mathrm{~d} \alpha}<0$ and $\frac{\mathrm{d} q}{\mathrm{~d} \alpha}>0$, denote the degree of upstream firm's concern about consumer surplus is significantly positive correlation with quantity and negative correlation with price. The consumer surplus rise when the upstream firm is consumer-friendly. And in this case, the increase in consumer surplus is greater than the decrease in total profits of firms, resulting in the rise of social welfare.

\subsection{The Comparison of the Social Welfare and Consumer Surplus}

According to lemma 1 and lemma 2, social welfare is positive correlated with the degree of upstream firm's concern about consumer surplus under centralized bargaining, and social welfare and the degree of upstream firm's concern about consumer surplus is inverted U-shaped relationship under decentralized bargaining. In which case social welfare is higher?

According to the above analysis, we can get that when the consumer-friendly upstream firm is involved in a centralized bargaining with the downstream firms, the social welfare is $S W_{c}=\frac{3-2 \alpha}{(-2+\alpha)^{2}(1+\gamma)}$. And the social welfare is $S W_{d}=\frac{(2-\gamma)(6+2 \alpha(-2+\gamma)(1+\gamma)-\gamma(1+3 \gamma))}{\left(4-2 \gamma^{2}+\alpha(-2+\gamma)(1+\gamma)\right)^{2}}$ under decentralized bargaining.

\section{Proposition 1.}

When

$$
\frac{-6+\gamma(-1+3 \gamma)+\sqrt{4+\gamma\left(4+(-1+\gamma)^{2} \gamma\right)}}{2(-2+\gamma)(1+\gamma)}<\alpha \leq 1, \quad S W_{c}>S W_{d},
$$

when

$$
0 \leq \alpha<\frac{-6+\gamma(-1+3 \gamma)+\sqrt{4+\gamma\left(4+(-1+\gamma)^{2} \gamma\right)}}{2(-2+\gamma)(1+\gamma)}, S W_{c}<S W_{d},
$$

when

${ }^{3} S W \uparrow$ represents the social welfare raise. CS $\uparrow$ represents the consumer surplus raise. $N \Pi \downarrow$ denotes total profits of downstream and upstream firms decrease. 


$$
\alpha=\frac{-6+\gamma(-1+3 \gamma)+\sqrt{4+\gamma\left(4+(-1+\gamma)^{2} \gamma\right)}}{2(-2+\gamma)(1+\gamma)}, S W_{c}=S W_{d} .
$$

The intuition for proposition 1 is straightforward. As shown in Figure 2, area under the line (area $A$ ) expresses that the social welfare is greater when the upstream firm is involved in a decentralized bargaining with the downstream firms. When consider the online area (area $B$ ), the social welfare is greater if the consumer-friendly upstream firm is involved in a centralized bargaining with the downstream firms. It is intuitively plausible that if the consumer-friendly upstream firm's valuation over consumer surplus is sufficiently high and the product differentiation degree is sufficiently low, centralized bargaining is welfare-superior to decentralized bargaining. On the other hand, if the consumer-friendly upstream firm's valuation over consumer surplus is sufficiently low and the product differentiation degree is sufficiently high, decentralized bargaining is welfare-superior to centralized bargaining.

As shown in Figure 3, when the degree of concern is relatively low $\left(0<\alpha<\frac{2-\gamma-\gamma^{2}}{2+\gamma-\gamma^{2}}\right.$ area I), the social welfare increases with $\alpha$ under the two bargaining modes. And in this situation the social welfare under the decentralized bargaining is greater than under the centralized bargaining. When $\frac{2-\gamma-\gamma^{2}}{2+\gamma-\gamma^{2}}<\alpha<\frac{-6+\gamma(-1+3 \gamma)+\sqrt{4+\gamma\left(4+(-1+\gamma)^{2} \gamma\right)}}{2(-2+\gamma)(1+\gamma)}$ (area II), although the social welfare is negatively correlated with $\alpha$ under decentralized bargaining and

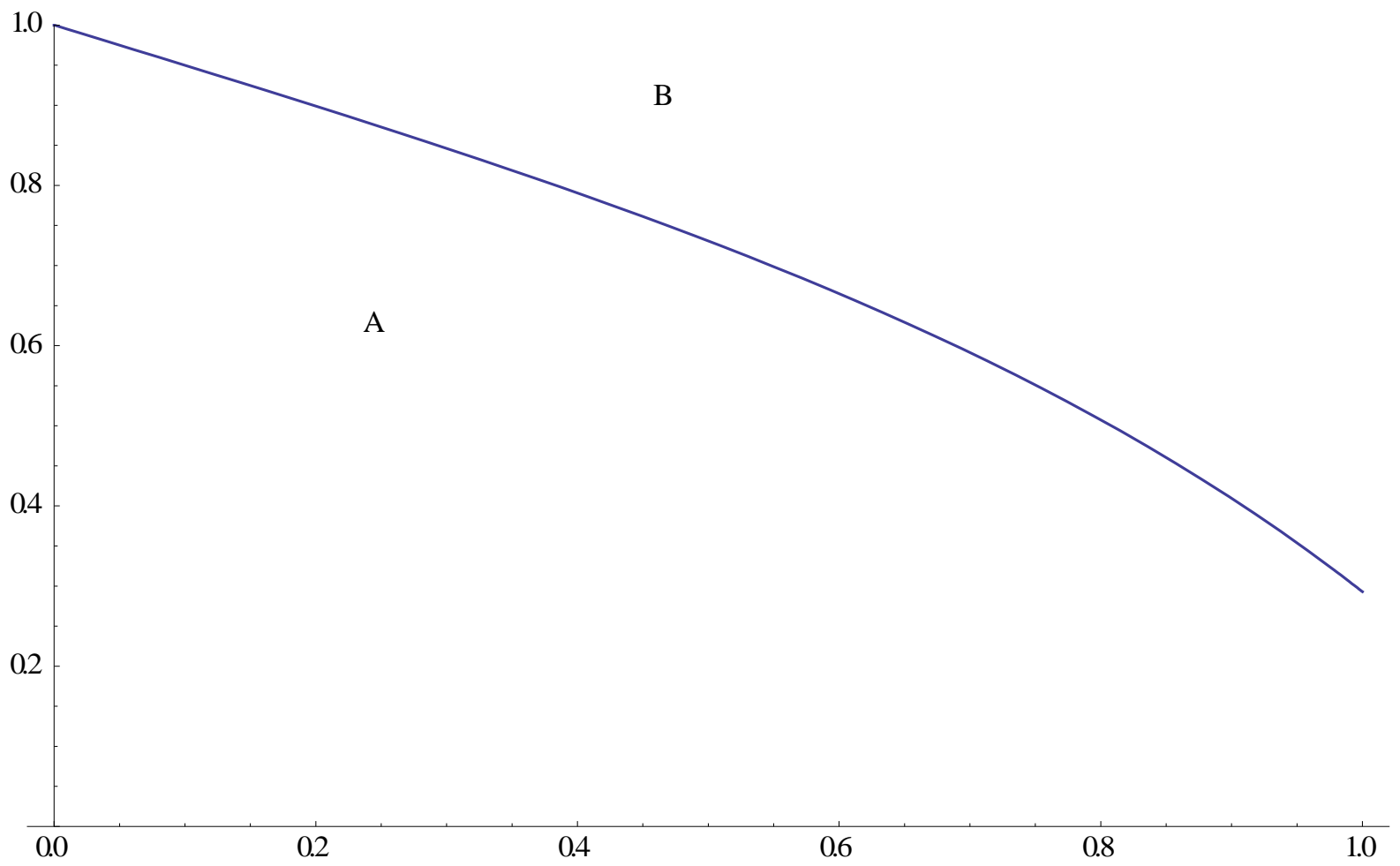

Figure 2. Social welfare comparison ( $X$-axis is $\gamma, Y$-axis is $\lambda)$. 


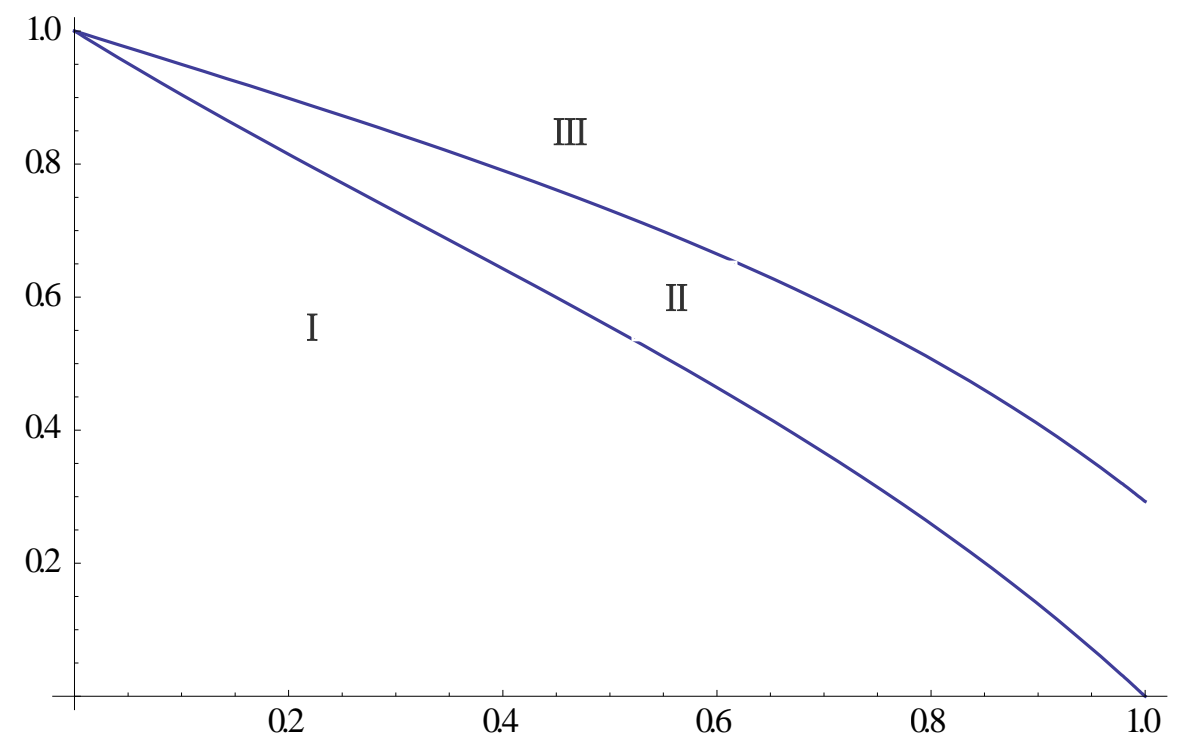

Figure 3. Social welfare comparison ( $X$-axis is $\gamma, Y$-axis is $\lambda)$.

positively correlated under centralized bargaining, the social welfare under the decentralized bargaining is also greater than under the centralized bargaining. But when the degree of concern is relatively high

$\left(\frac{-6+\gamma(-1+3 \gamma)+\sqrt{4+\gamma\left(4+(-1+\gamma)^{2} \gamma\right)}}{2(-2+\gamma)(1+\gamma)}<\alpha<1\right.$, area III), the social welfare

under the decentralized bargaining is less than under the centralized bargaining. In this situation, reduction in social welfare is sufficiently high under decentralized bargaining and added value of social welfare is sufficiently high under centralized bargaining.

The consumer surplus is $C S_{c}=\frac{1}{(1+\gamma)(2-\alpha)^{2}}$, when that the upstream firm involves in a centralized bargaining with the downstream firms. And the consumer surplus is $C S_{d}=\frac{(2-\gamma)^{2}(1+\gamma)}{\left(4+\gamma^{2}(-2+\alpha)-2 \lambda-\gamma \alpha\right)^{2}}$ under decentralized bargaining mode. It can be checked that the consumer surplus increase as $\alpha$ rises under two bargaining modes. In which case the consumer surplus is higher?

Proposition 2. Decentralized bargaining generates higher consumer surplus as compared to centralized bargaining, irrespective of both the product differentiation degree and the upstream firm's valuation over consumer surplus.

Proof:

$$
\Delta=C S_{c}-C S_{d}=\frac{4 \gamma[-4-\gamma+\alpha(2+\gamma)]}{(-2+\alpha)^{2}(1+\gamma)[-4+\alpha(2+\gamma)]^{2}}<0 .
$$

Centralized bargaining is that downstream firms together to bargain with the upstream firm and decentralized bargaining is that downstream firms respectively bargains with the upstream firm. So when the downstream firms get together, more conducive to protect their own profits, what is mean that more 
convenient to occupy the consumer surplus. So the consumer surplus is less under the centralized bargaining.

\section{Conclusions}

In this paper we find that when the consumer-friendly upstream firm is involved in a centralized bargaining with the downstream firms, choosing price contract is the best strategy for the final goods producers which is same to Leonard F.S. Wang et al. (2016) [8]. However when the consumer-friendly upstream firm is involved in a decentralized bargaining with the downstream firms, quantity contract is the dominant strategy for the downstream firm which is same to Alipranti et al. (2014) [6]. Moreover, if the consumer-friendly upstream firm's valuation over consumer surplus is sufficiently high and the product differentiation degree is sufficiently low, centralized bargaining is welfare-superior to decentralized bargaining. On the other hand, if the consumer-friendly upstream firm's valuation over consumer surplus is sufficiently low and the product differentiation degree is sufficiently high, decentralized bargaining is welfare-superior to centralized bargaining. We also show that decentralized bargaining generates higher consumer surplus as compared to centralized bargaining, irrespective of both the product differentiation degree and the upstream firm's valuation over consumer surplus. And only under the decentralized bargaining, upstream enterprises can better achieve its goal.

Finally, we must admit that our model is restrictive. For example, we only considered one firm in the upstream market and two firms in the downstream market. Furthermore, we do not allow the downstream market is free entry. Extend our model to these direction remains for future research.

\section{References}

[1] Singh, N. and Vives, X. (1984) Price and Quantity Competition in a Differentiated Duopoly. The RAND Journal of Economics, 546-554. https://doi.org/10.2307/2555525

[2] Cheng, L. (1985) Comparing Bertrand and Cournotequilibria: A Geometric Approach. The RAND Journal of Economics, 146-152. https://doi.org/10.2307/2555596

[3] Vives, X. (1985) On the Efficiency of Bertrand and Cournot equilibria with Product Differentiation. Journal of Economic Theory, 36, 166-175. https://doi.org/10.1016/0022-0531(85)90086-9

[4] Villas-Boas, S.B. (2007) Vertical Relationships between Manufacturers and Retailers: Inference with limited Data. The Review of Economic Studies, 74, 625-652. https://doi.org/10.1111/j.1467-937X.2007.00433.x

[5] Bonnet, C. and Dubois, P. (2010) Inference on Vertical Contracts between Manufacturers and Retailers Allowing for Nonlinear Pricing and Resale Price Maintenance. The RAND Journal of Economics, 41, 139-164. https://doi.org/10.1111/j.1756-2171.2009.00093.x

[6] Alipranti, M., Milliou, C. and Petrakis, E. (2014) Price vs. Quantity Competition in a Vertically Related Market. Economics Letters, 124, 122-126. https://doi.org/10.1016/j.econlet.2014.05.002

[7] McAfee, R.P. and Schwartz, M. (1995) The Non-Existence of Pairwise-Proof Equi- 
librium. Economics Letters, 49, 251-259.

https://doi.org/10.1016/0165-1765(95)00681-5

[8] Basak, D. and Wang, L.F. (2016) Endogenous Choice of Price or Quantity Contract and the Implications of Two-Part-Tariff in a Vertical Structure. Economics Letters, 138, 53-56. https://doi.org/10.1016/j.econlet.2015.11.026

Submit or recommend next manuscript to SCIRP and we will provide best service for you:

Accepting pre-submission inquiries through Email, Facebook, LinkedIn, Twitter, etc. A wide selection of journals (inclusive of 9 subjects, more than 200 journals) Providing 24-hour high-quality service User-friendly online submission system Fair and swift peer-review system Efficient typesetting and proofreading procedure Display of the result of downloads and visits, as well as the number of cited articles Maximum dissemination of your research work

Submit your manuscript at: http://papersubmission.scirp.org/ Or contact jss@scirp.org 